\title{
Conversos y nobleza o las desventuras de un corregidor
}

\author{
Bernardo José LÓPEZ BELINCHÓN
}

Alba de Tormes, mediados de enero de 1622. Las frías noches del invierno castellano invitaban a reunirse al amor de la lumbre. Junto a ella brotaba la conversación sobre los últimos acontecimientos o sobre viejas historias. Los rumores que circulaban por el pueblo encontraban en estas tertulias un terreno abonado para su crecimiento y difusión.

En casa del licenciado Jerónimo Martínez de Zúñiga, oidor en el consejo del duque de Alba, se habían reunido algunos importantes personajes de la vida local como Juan González Bretón, regidor y familiar del Santo Oficio, y el licenciado Miguel de Benavides. El asunto que acaparaba su atención era «lo que se oía en los corrillos de la plaza» sobre el reciente entierro del doctor Enríquez «que se decía había sido una gran bellaquería» por haberse realizado con extraños ritos que desprendían un intenso aroma a ceremonias criptojudaicas ${ }^{1}$.

La posición social de Enríquez, médico personal del duque de Alba, señor de la villa, y el que su yerno fuese el corregidor seño-

1 La mayor parte de la información utilizada en este artículo proviene del proceso incoado en 1622 por el Santo Oficio de Valladolid al corregidor D. Andrés López de Fonseca. Este proceso se conserva en el Archivo Diocesano Conquense [= ADC], Inquisición, Leg. 418 (expt. 5868). Para completar la información deben consultarse: ADC, Inq., Legs. 410 (expt. 5766) y 404 (expt. 5713), ambos del tribunal de Valladolid correspondientes al licenciado D. Manuel Méndez de León y a Ana Sánchez de Guevara, respectivamente. Otros datos complementarios aparecen en ADC, Inq., Legs. 487 (expt. 6536) y 483 (expt. 6513), procesos realizados en Cuenca en 1652 al doctor Andrés de Fonseca y a su esposa D. ${ }^{a}$ Isabel Enríquez. 
rial de Alba de Tormes daban aún más pábulo a los rumores. El origen portugués del médico y la casta judeoconversa que se les atribuía en el pueblo a ambos eran otros poderosos indicios para avivar la creciente llama de la sospecha. ¿Quién era este galeno que suscitaba tanto recelo?

El doctor Jorge Enríquez era natural de la ciudad lusa de La Guarda, en la región de la Beira Alta. Era esta una zona con importante presencia de judeoconversos tras el bautismo forzoso de los judíos portugueses y de sus hermanos de religión recién llegados de Castilla, como lo demuestra el que un 51,5\% de los judaizantes de origen portugués procesados por el Santo Oficio de Cuenca entre 1600 y 1665 fuera originario de la Beira Alta ${ }^{2}$.

Nació a mediados del siglo XVI en el seno de una de estas familias de cristianos nuevos de origen judío. Su padre vivía de su hacienda, lo que indica una desahogada posición económica familiar que les permitió a él y a su hermano Gaspar cursar estudios universitarios. Esta práctica fue característica de los hijos de las familias pudientes, pero infamadas por su raza, de los pueblos y aldeas de la Beira y Tras-os-Montes, comarcas con una alta densidad de conversos. Estos muchachos, según Caro Baroja, «luego de hacer sus estudios primarios con algún dómine de la localidad solían ir a la universidad de Coimbra» ${ }^{3}$. Este fue el camino que siguieron los hermanos Enríquez, al igual que otros vástagos de familias judeoconversas como Miguel de Silveira, médico y literato, natural de Celorico de Beira, a tan sólo una veintena de kilómetros de La Guarda.

Una vez en Coimbra, Jorge Enríquez eligió los estudios de medicina y su hermano los de leyes. En esta universidad existía una brillante pléyade de profesores cristianos nuevos, especialmente en la facultad de medicina, como Antonio Gómez, más tarde procesado por la Inquisición castellana, o el famoso doctor Antonio Homem. Entre ellos, sin duda, encontró el joven estudiante ayuda y protección.

\footnotetext{
${ }^{2}$ Bernardo J. López BelinChón, Honra, libertad y hacienda, de próxima publicación por el Instituto Internacional de Estudios Sefardíes y Andalusíes de la Universidad de Alcalá.

3 J. CARo BAROJA, Inquisición, brujería y criptojudaísmo (Barcelona 1974, $3^{\text {a }}$ ed.) pág. 121.
} 
La popularidad de la profesión médica entre los conversos está bien documentada. El profesor Yerushalmi, en su estudio sobre el doctor Cardoso, otro famoso médico converso oriundo de la Beira, atribuye el éxito de la profesión entre este grupo a las posibilidades de mejora de posición social que ofrecía a la elite intelectual de una minoría excluida de otras muchas actividades por los prejuicios de la limpieza de sangre, amén de haber sido esta una actividad tradicional de los judíos hispanos ${ }^{4}$.

Tras estudiar en Coimbra, pasó a la prestigiosa Universidad de Salamanca. Otros muchos estudiantes lusos realizaron el mismo periplo, como el doctor Miguel Lobo, médico portugués de origen converso procesado en Cuenca en 1616, quien estudió en Coimbra y se graduó en Salamanca ${ }^{5}$, o el ya citado doctor Miguel Silveira. El puesto de lector de artes que Enríquez alcanzó en la universidad salmantina muestra su brillante carrera académica. Vuelto a Coimbra, su prestigio y sus apoyos en el mundo universitario le permitieron, primero, ser sustituto en la cátedra de Avicena, para después ocupar la cátedra de práctica de medicina, ambas en la universidad de la ciudad lusa.

$\mathrm{Su}$ rastro se pierde en este momento para reaparecer en los años ochenta del siglo XVI asentado definitivamente en Castilla, aunque tenemos constancia de que su esposa e hijos residieron en La Guarda al menos hasta 1590 . Su paso a Castilla debe relacionarse con la primera gran oleada represiva de la Inquisición lusa sobre los conversos y que Veiga Torres data entre 1580 y $1600{ }^{6}$. La situación debió tornarse insostenible como lo demuestra el que sus padres, según testimonios posteriores, fueron relajados por judaizantes.

En esta coyuntura, Castilla, especialmente tras la anexión de Felipe II, se presentaba como una buena salida para muchos judeoconversos. Entre los huidos a fines del siglo XVI, según Lucio de Acevedo, eran muy numerosos los médicos, hasta tal punto que

${ }^{4}$ Y. H. Yerushalmi, De la corte de España al gueto italiano: Marranismo y judaísmo en la España del XVII, El caso Isaac Cardoso (Madrid 1989) pág. 50.

5 ADC, Inq., Leg. 383 (expt. 5439).

6 J. VEIGA TORRES, «Uma longa guerra social: os ritmos da repressão Inquisitorial em Portugal», Revista de Historia Económica y Social (Lisboa 1978) págs. 55-68. 
en 1614 los inquisidores lusos se mostraban alarmados por la falta de galenos en el reino, en su mayoría emigrados a Castilla ${ }^{7}$.

El doctor Enríquez se estableció junto a la raya fronteriza y ejerció como médico en algunas aldeas de Coria. Muy pronto entró al servicio del duque de Alba, a la sazón marqués de Coria, como su médico de cámara. Fue, sin duda, su prestigio profesional lo que le permitió acceder a este puesto, prestigio refrendado y consolidado por los libros que escribió. El primero, publicado en Salamanca en 1594, aunque con licencia dada en Valladolid en 1592 , estaba dedicado a temas de dietética ${ }^{8}$. Su segunda obra, el famosísimo Retrato del perfecto médico, fue editada en Salamanca en 1595 y dedicada a D. Antonio Álvarez de Toledo, duque de Alba. La fecha de edición de este libro y la dedicatoria que contiene confirman que estaba instalado en la corte ducal desde hacía tiempo.

El prólogo de ese segundo libro incluía un soneto que le había dedicado Lope de Vega, llamándole «médico perfecto, heroico y sabio», prueba de la existencia de una relación de amistad entre ambos en los años - de 1590 a 1595- en que el Fénix de los Ingenios fue secretario del duque de Alba ${ }^{9}$.

D. Antonio Domínguez Ortiz ya señaló con acierto el importante papel que los judíos ejercieron como servidores de reyes y nobles ocupando puestos de consejeros, secretarios, mayordomos, tesoreros $\mathrm{y}$, por supuesto, de médicos ${ }^{10}$. Los judeoconversos, siguiendo esta tradición, vieron en el servicio al Rey y a las casas nobiliarias el medio de obtener unos poderosos valedores en las redes clientelares características de las sociedades modernas. Estos apoyos les permitieron un ascenso social muy difícil de obtener por otros caminos cerrados para ellos por la mácula de su sangre. La nobleza a su vez buscaba en estos servidores, con una débil

7 J. L. de Azevedo, Historia dos Cristãos Novos portugueses (Lisboa 1921).

8 J. EnRÍQUeZ, De Régimen cibi atque potus et de caeterarum reru non naturalium usu nova enarratio (Salamanca 1594).

9 Así le elogiaba Lope de Vega en los siguientes versos (p. 10): «Pero quedara más perfectamente / el médico perfecto retratado / retratándose Enríquez a sí mismo /... / Traspuesta planta al castellano suelo / del venturoso vuestro lusitano».

10 A. Domínguez ORTiz, La clase social de los conversos en Castilla en la Edad Moderna (Madrid 1955; ed. facsímil, Granada 1991). 
posición social, la fidelidad y el celo en el desempeño de sus cargos nacidos del agradecimiento por la protección recibida.

Hemos señalado ya cómo el doctor Enríquez pronto se acogió al padrinazgo del duque de Alba y veremos cómo casi toda su familia sirvió a la casa ducal en diversos puestos. Este no es el único caso de eminentes médicos portugueses que gozaron del patrocinio nobiliario: recordemos a Fernando Cardoso, protegido del duque de Medina de Rioseco. Al doctor Silveira, la intervención de su valedor, el duque de Medina de las Torres, le permitió escapar hacia Nápoles cuando la Inquisición comenzó a centrar sus pesquisas sobre él. Incluso el Obispo de La Guarda tuvo como médico al ya citado doctor Lobo, procesado por judaizante ${ }^{11}$.

Más extensa es la lista de judeoconversos que actuaron en otros puestos de las administraciones señoriales, o incluso como prestamistas de las haciendas de muchos nobles. Estos servicios, como se verá, eran muy peligrosos por los odios e inquinas que suscitaban en muchos sectores sociales.

El doctor Enríquez se instaló en Alba de Tormes, sede de la corte ducal. Por su cercanía a la persona del duque, allí se relacionaba con la elite de la villa y de la administración señorial. Su elevada posición dentro de la microsociedad local no dejaba de despertar suspicacias en un lugar donde todos se conocían.

La figura del médico en la Edad Moderna tiene un carácter bivalente. Por un lado sus conocimientos le dotaban de un aura casi mágica. Al médico se le atribuía un misterioso poder sobre la vida y la muerte que incluso llegaba a inspirar miedo. Por otra parte se acudía a ellos con fe, buscando una curación no siempre posible. El precario equilibrio entre confianza y recelo solía inclinarse hacia la suspicacia cuando el paciente no obtenía la ansiada mejoría. La situación aún se tornaba más inestable en el caso del doctor Enríquez por su origen portugués.

J. P. Dedieu ha señalado que en las comunidades locales el extranjero era visto como la imagen del mal en su más amplio sentido. Lo malo siempre provenía del exterior. Esas imágenes

${ }^{11}$ Numerosos nobles tuvieron médicos de origen converso, como los duques de Escalona, del Infantado o de Pastrana, cuyo médico, Simón Núñez Cardoso, fue procesado en 1652 por el Santo Oficio de Cuenca acusado de judaizante (ADC, Inq., Leg. 487 [expt. 6538]). 
populares en buena parte se debían a una activa propaganda inquisitorial dirigida en tal dirección ${ }^{12}$. Si además de extranjero se era portugués, las sospechas de criptojudaísmo eran inmediatas.

La imagen que de Enríquez tenían sus convecinos no debía estar muy alejada de lo descrito arriba, como se deduce de la opinión de un fraile franciscano de Alba, escandalizado ante ciertos comportamientos del galeno «y más considerando que era portugués y médico». Tres eran las acusaciones que, en forma de rumor, se le hacían: casta de cristiano nuevo descendiente de judíos y portugués de nación; extraños hábitos, especialmente alimenticios, como no matar cerdos en su casa o tirar la manteca; y por último ser mal cristiano por no asistir a la iglesia, no confesar e incluso no jurar por Cristo. Todo ello, según varios vecinos, generaba «una mala opinión del doctor Enríquez en la villa». Un notario del Santo Oficio en la villa llegó a ponerle espías para comprobar si asistía a misa y en caso negativo avisar a la Inquisición ${ }^{13}$.

Esta situación, casi de libertad vigilada, no era singular. Otros dos médicos de origen portugués, el doctor Lobo y el licenciado Villanueva, médicos de Budia y Moya respectivamente, tras haber sido sometidos a una estrecha vigilancia fueron denunciados por sus vecinos al tribunal de la Inquisición de Cuenca con idénticas imputaciones: ser cristianos nuevos portugueses, con hábitos extraños y malos cristianos. En el caso del licenciado Villanueva, un sacerdote de la localidad y sus amigos se repartieron por las iglesias para comprobar si iba a misa y «durante varios domingos $\mathrm{y}$ fiestas estuvieron mirando si iba o no» ${ }^{14}$.

A diferencia de los casos anteriores, el doctor Enríquez y su familia gozaban de una sólida posición dentro de la villa merced a la protección que les dispensaba el duque de Alba. Dos de los yernos del médico, el doctor Andrés de Fonseca y el licenciado Manuel Méndez de León, eran corregidores de sendas villas del

12 J. P. DedIEU, L'administration de la foi: L'Inquisition de Tolede (XVII ${ }^{e}$-XVIII ${ }^{e}$ siècle) (Madrid 1989).

13 ADC, Inq., Leg. 418 (expt. 5868).

${ }^{14}$ En ADC puede consultarse el proceso del doctor Lobo (Inq., Leg. 383 [expt. 5439]) y las testificaciones contra Villanueva (Leg. 434 [expt. 6128]). A este se le acusa, entre otras cosas, de curar a los pacientes tras consultar a un mono que tenía en su casa. 
duque: Alba y el Barco, respectivamente. Uno de sus hijos, D. Rodrigo Enríquez, era alcalde mayor de la villa de Granadilla; otro, D. Diego Enríquez, poseía un beneficio en Salvatierra de Alba y la esposa del doctor, Doña Blanca, era dama de la duquesa de Huéscar. Sin duda era una espléndida situación. Pero la muerte del doctor Enríquez, al privar a la familia de su principal apoyo, vendría a trastocarlo todo.

Tras el entierro se desataron los rumores sobre las extrañas circunstancias que rodearon la defunción y la inhumación del cadáver. Estas habladurías fueron el desencadenante de un proceso inquisitorial en el que se unieron de forma inextricable odios personales, conflictos políticos y sospechas de herejía.

Desde el mismo día del sepelio se habían venido reuniendo en casa de Antonio Rodríguez, escribano del consistorio de Alba y familiar del Santo Oficio, algunas personas de peso en la vida local. Al igual que en casa del licenciado Martínez Zúñiga el escándalo provocado por los ritos con que se enterró al médico del duque era el centro de todas las conversaciones. Rodríguez, en cuanto que familiar del Santo Oficio, decidió asumir su responsabilidad y junto con otros dos familiares, Juan González Bretón y D. Antonio Castilla de Zúñiga, y el notario de la Inquisición Gabriel González Bretón acordaron poner los hechos en conocimiento de la Inquisición.

Para evitar que el yerno del difunto, el corregidor Fonseca, pudiese obstaculizar su denuncia, acudieron simultáneamente a los comisarios inquisitoriales de Alba y Salamanca, pues el objetivo último de la acusación era el propio corregidor. Las denuncias llegaron al Tribunal de Valladolid y el 25 de febrero de 1622 los inquisidores comenzaron a tomar declaraciones en Alba ${ }^{15}$. El proceso había comenzado.

Las personas llamadas a declarar y las informaciones que aportaron nos permiten apreciar la existencia dentro de la villa de un bando integrado por algunos miembros de la elite local que por diferentes motivos tenían cuentas pendientes con el corregidor, máximo representante del poder señorial en la villa.

El poder de la nobleza en sus estados necesitaba de mecanismos

15 ADC, Inq., Leg. 418 (expt. 5868), y Archivo Histórico Nacional [= AHN], Inq., Leg. 3210. 
institucionales para un control efectivo del territorio. La figura del corregidor señorial debe situarse entre estos mecanismos de control. Asumía la máxima autoridad en la villa señorial bajo su jurisdicción, ejerciendo funciones gubernativas y judiciales en primera instancia ${ }^{16}$. Como defensor de los intereses señoriales, eran muy frecuentes los conflictos con colectivos o individuos cuyos intereses particulares no coincidían con los del señor en cuestiones tales como las competencias concejiles, el cobro de rentas, la usurpación de tierras, derechos de caza, exenciones de los privilegiados y un largo etcétera. Muchas veces lo que se dilucidaba era más el prestigio social de las partes que cuestiones materiales.

El ejercicio de las funciones inherentes a su cargo por parte del corregidor Fonseca y su carácter altanero le ganaron muchas enemistades entre los miembros de una oligarquía local que trataban de obtener los máximos beneficios de su posición, a costa muchas veces de los intereses señoriales.

Monsalvo Antón, en su estudio sobre Alba de Tormes a fines del siglo Xv, indica cómo los puestos de agentes señoriales, incluido el de corregidor, eran confiados casi siempre a servidores o clientes del duque. El poder político del corregidor radicaba exclusivamente en el apoyo del señor, por lo que no podía imponer una decisión suya ante la oposición de los regidores sin contar con un aval señorial directo ${ }^{17}$. Por estas razones las acusaciones de herejía y la acción del Santo Oficio, junto con la pérdida de su principal valedor ante el duque de Alba, parecían ofrecer el medio y el momento idóneo para librarse de un corregidor molesto.

En sociedades a pequeña escala como la de Alba los rumores sobre la vida privada eran un medio más de atacar la posición de un individuo ante la comunidad. Cuando estos cuestionaban la reputación y la fama, ingredientes básicos del prestigio social, era necesaria una defensa a ultranza. Reputación, fama y honor eran determinantes para mantener el status y poder contar con seguidores y con protectores, como en este caso el duque de Alba ${ }^{18}$.

16 I. Atienza HeRnÁndeZ, Aristocracia, poder y riqueza en la España moderna (Barcelona 1987).

17 J. M. Monsalvo Antón, El sistema político concejil: El ejemplo del señorío medieval de Alba de Tormes y su concejo de villa y tierra (Salamanca 1988) pág. 356.

18 J. CASEY, Historia de la familia (Madrid 1990) pág. 75. 
Contra tan preciados valores y tan difíciles de proteger, dirigieron sus dardos los acusadores en el proceso inquisitorial. Sus declaraciones no aclaran el origen exacto de los rumores. Todos lo habían oído de otros o se hacían eco del «ruido y murmuraciones que se levantaron» en la villa ${ }^{19}$.

El corregidor Fonseca identificó claramente el origen de las murmuraciones. Señaló desde el primer momento a Antonio Rodríguez como la fuente «y de aquí se publicó lo susodicho en la dicha villa de Alba» ${ }^{20}$. Sin duda sabía quiénes eran sus enemigos.

Junto a Antonio Rodríguez, al que ya vimos promover la denuncia, podemos identificar al resto de los opositores al corregidor entre los testigos de la acusación: Juan González Bretón, regidor y familiar de la Inquisición, y su hermano Gabriel, presbítero y notario del Santo Oficio, ambos ricos propietarios de tierras; el licenciado Miguel de Benavides; Celedón de Gamboa, procurador de causas del número de la villa; el licenciado Martínez Zúñiga, oidor del consejo del duque; el sacerdote Alonso de Cepeda; Juan Fernández Ortiz, clérigo presbítero beneficiado y hermano del alcalde mayor de la villa; D. Antonio Castilla de Zúñiga, regidor perpetuo y familiar; y fray Juan Martínez, monje franciscano, representante de los intereses de su monasterio. Poderosos enemigos todos ellos con importantes cargos en el concejo y en la estructura inquisitorial local, prácticamente copada ya en esta época por las elites locales ansiosas del honor y de los privilegios que acompañaban a las familiaturas ${ }^{21}$.

El grupo vio respaldadas sus declaraciones con los testimonios de amigos y clientes, como Juan Montañés, portero del consejo del duque, y su esposa, quienes debían el empleo a la protección del licenciado Martínez Zúñiga.

La acusación central contra el corregidor era su participación con un papel preeminente en las ceremonias realizadas para el entierro del doctor Enríquez. Los actos vistos como sospechosos eran hacer más honda la fosa para enterrarlo en tierra virgen;

19 ADC, Inq., Leg. 418 (expt. 5868).

20 ADC, Inq., Leg. 418 (expt. 5868).

21 DEDIEU L'administration de la foi; B. BENASSAR, Inquisición española: poder político y control social (Barcelona 1981, $2^{\text {a }}$ ed.); y B. J. LÓPEZ BELINCHÓN, «La memoria de la infamia", en J. Martínez Millán (dir.), Felipe II (1527-1598): Europa y al Monarquía Católica (Madrid 1998) vol. III págs. 271-289. 
amortajar el cuerpo, previamente lavado, con ropas nuevas; ponerle monedas de plata sobre la cabeza; negarse a recibir auxilio espiritual antes de la muerte; dar un grito todos los familiares en el momento de expirar el difunto y ayunar todos tras el fallecimiento. Tales actos coincidían con gran exactitud con algunos de los señalados como indicios de judaísmo en los Edictos de $\mathrm{Fe}$, bien conocidos por todos ${ }^{22}$.

Esas acusaciones concretas se reforzaron con las suspicacias que despertaban los portugueses en las pequeñas comunidades y que ya vimos dirigidas contra el doctor Enríquez. Otra vez se repiten las sospechas de herejía provocadas por su ascendencia judeoconversa, en tanto que portugueses, sus hábitos diferentes, especialmente los alimenticios, y su escasa asistencia a las ceremonias religiosas. Un testigo definía a Fonseca como «mal cristiano, jurador, testimoniero y mentiroso» ${ }^{23}$. Este segundo bloque de imputaciones respondía a los tópicos creados sobre los recién llegados de Portugal y que circulaban por la sociedad castellana, especialmente en el mundo rural. Idénticas acusaciones pueden encontrarse en muchos de los procesos contra judaizantes de origen luso incoados, entre otros, en el Tribunal de Cuenca.

El cargo y el mencionado carácter arrogante del corregidor Fonseca habían generado una fuerte hostilidad hacia él entre algunos vecinos. Consciente de ello, desde el comienzo atribuyó todas las acusaciones que se le hacían a una «confederación contra él» ya que «como había sido juez tiene muchos quejosos por haber procedido contra ellos». Pocos días después del tan comentado entierro, Juan González Bretón, uno de los acusadores, le había dicho «con ademán y meneando la cabeza, señor corregidor, amigo y chinche en el ojo, el comisario Nogal fue a mi casa y no es todo sano». Al mismo tiempo por el pueblo se murmuraba que «el oidor Zúñiga y el Príncipe [Gabriel González Bretón] le andan haciendo la cama al corregidor» ${ }^{24}$.

El licenciado Martínez Zúñiga y los hermanos González Bretón se presentan como enemigos acérrimos del corregidor. Algún

22 M. JIMÉNEZ MONTESERÍN, Introducción a la Inquisición española (Madrid 1980).

23 ADC, Inq., Leg. 418 (expt. 5868).

${ }^{24}$ Las citas que siguen corresponden al proceso señalado en nota 23. 
tiempo atrás, el primero había ordenado prender y encarcelar a Fonseca acusándole de haber desobedecido un auto del consejo del duque que aquel le había notificado. Sólo la intervención señorial directa inclinó la balanza a favor del corregidor. Poco antes, Martínez Zúñiga lo había denunciado por sacar veinte fanegas de la alhóndiga de Alba sin pagar. Ignoramos si esto ocurrió antes o después del importante pleito de los perdigones que ambos sostuvieron.

La caza de la tierra de Alba era un privilegio señorial frecuentemente vulnerado por las oligarquías locales. En este contexto el duque ordenó al corregidor matar los perdigones de caza y tomar los arcabuces de varias personas de la villa. Uno de los afectados por la medida fue Martínez Zúñiga que, por la consiguiente afrenta a su prestigio, inició un largo pleito por considerar abusivo el comportamiento de Fonseca. No sólo su crédito, sino también sus intereses económicos, sufrieron un duro golpe cuando en otra actuación el corregidor castigó a los criados de la granja de los religiosos de San Jerónimo y «prendió y penó» a sus ganados, ya que Martínez Zúñiga tenia «granjería y compañía» con estos monjes. Los procesos generados por estas medidas sirvieron de pretexto para una nueva denuncia del corregidor Fonseca contra Martínez Zúñiga por coaccionar a los testigos para que mintiesen. El odio entre ambos debía ser profundo.

Unidos por una estrecha amistad a Martínez Zúñiga estaban los hermanos González Bretón. También habían tenido desavenencias con el corregidor, quien había difundido el rumor de que descendían de moriscos. Todos utilizaban la sospecha sobre la limpieza de sangre como arma contra sus enemigos ${ }^{25}$. Uno de los hermanos, Juan, regidor y familiar, había perdido su oficio de recaudador de la villa por la intervención de Fonseca. Al otro hermano, Gabriel, le incoó un proceso a raíz de las denuncias de varios jornaleros portugueses que le acusaban de que «les amenazaba con el Santo Oficio diciéndoles que puede hacer y deshacer y les manda vayan a sus viñas quedándose muchas veces con su jornal».

El sacerdote Alonso de Cepeda, amigo de los anteriores y otro de los acusadores, había tenido «graves encuentros» con el corre-

${ }^{25}$ Bernardo J. LÓPEZ BELINCHÓN Las últimas hogueras (en prensa). 
gidor a raíz de la acusación que le hizo de «hombre de poca conciencia y alma, le mostró sus vergüenzas a una monja mientras con la otra le enseñaba el santísimo sacramento».

Otro grupo de denunciantes, unidos a los ya citados por lazos de amistad e interés, se formó en torno a Antonio Rodríguez, gravemente afrentado por la prisión que el corregidor hizo de su hijo. Su amigo D. Antonio Castilla de Zúñiga, regidor perpetuo y familiar del Santo Oficio, había sido obligado por Fonseca a «devolver muchos maravedíes que tenía usurpados a la villa».

Un conocido del regidor, Juan Fernández Ortiz, había sido acusado por el corregidor Fonseca de solicitante, aunque parece que sin pruebas. Más grave había sido el enfrentamiento con su hermano, el alcalde mayor de la villa, a cuya esposa Fonseca «le quitó un estrado que puso delante de la mujer del corregidor y lo quiso quemar», una ofensa al prestigio de la familia difícil de perdonar. Por último, Celedón de Gamboa y el licenciado Benavides, asiduos ambos a las reuniones en casa de Antonio Rodríguez, también tenían agravios pendientes con el corregidor.

De todo lo hasta aquí expuesto se infiere que la mayoría de los testigos de la acusación habían tenido, por razones de muy diversa índole, algún tropiezo con el corregidor. Esto nos permite afirmar que las denuncias, realizadas en el momento en que Fonseca acababa de perder su principal valedor ante la cúspide de la pirámide clientelar señorial, no tenían un móvil exclusivamente religioso, de lucha contra la herejía. La Inquisición fue usada en esta coyuntura como un arma más, acaso la fundamental, en una lucha política y social. Política por los enfrentamientos nacidos de esferas de poder en colisión, la señorial y la de la oligarquía local. Social porque se dilucidaban asuntos de honor y pública fama, determinantes del puesto a ocupar dentro de la comunidad.

El corregidor Fonseca, conocedor desde el comienzo de los orígenes y móviles del ataque, parecía tranquilo, dominando la situación. Sólo una sombra parecía amenazar su seguridad y esta provenía de su pasado. ¿A qué temía el corregidor Fonseca?

El doctor Andrés de Fonseca había nacido hacia 1585 en Mirandela, en la comarca lusa de Tras-os-Montes, tierra de judeoconversos. Su familia pertenecía a la elite local de los conversos de la villa. Su padre era hombre de negocios y juez de los estancos del 
rey en Portugal. Su abuelo vivía de su hacienda, al igual que algunos de sus tíos, síntoma inequívoco de gozar de una desahogada posición económica.

En 1586 pasó con sus padres a Castilla, coincidiendo con la primera gran oleada represiva de la Inquisición portuguesa hacia esta minoría, ya señalada más arriba. Tras una breve estancia en Medina de Rioseco, tierra señorial con una nutrida colonia de conversos tanto de origen castellano como portugués, se asentaron en Madrid.

En la Corte comenzó su formación que continuó en Verín cuando sus padres se trasladaron allí en 1591. La localidad gallega, también tierra señorial, había atraído a un gran número de emigrados portugueses que no habían logrado integrarse socialmente por su doble carácter de extranjeros y sospechosos de herejía. Luis López, el padre de Fonseca, se dedicaba al comercio y su esposa, Isabel de Acosta, se ocupaba de dirigir el hogar e hilar seda en su casa junto con otras mujeres portuguesas, muchas de ellas familiares suyas.

Sus padres, al igual que los de otros muchos jóvenes conversos, pusieron un gran esmero en la educación de sus hijos, buscando a través de los estudios una salida a la situación de discriminación social que padecían. Al menos tres de los cinco hermanos varones, entre ellos Andrés, estudiaron en el colegio de los jesuitas de Monterrey, práctica esta de acudir a los colegios jesuíticos muy extendida entre los conversos, quizás por los menores prejuicios de los seguidores de San Ignacio respecto a la limpieza de sangre.

En 1602 la Universidad de Salamanca acogía ya en sus aulas a dos de los hermanos, Andrés y Gaspar, que cursaban estudios de leyes y medicina respectivamente. En este momento la comunidad lusa de Verín fue desarticulada por la intervención del Santo Oficio de Galicia.

Una visita rutinaria de los inquisidores gallegos al valle de Monterrey en 1602 fue el «principio de estos negocios». Un grupo de criados y vecinos de los portugueses creyeron reconocer en las prácticas descritas por el edicto de fe grandes similitudes con los extraños comportamientos de estos extranjeros, poco integrados en la comunidad y tan sospechosos de herejía. Las acusaciones hacen referencia, una vez más, a hábitos alimenticios (no comer 
tocino, guisar con aceite, degollar las aves o practicar ayunos no católicos) y a su dudoso cristianismo, tanto por su casta de cristianos nuevos como por sus costumbres («no tienen cruces ni santos ni imágenes» o trabajar los domingos hilando seda).

Luis López y su esposa fueron apresados junto con varios familiares y otros muchos portugueses de la villa, ascendiendo a veinticinco los votados a prisión con secuestro de bienes. Las confesiones de los reos, especialmente las de un primo de Fonseca, Francisco Álvarez, estudiante con los jesuitas de Monterrey, pusieron al descubierto un activo núcleo judaizante unido por tupidos vínculos familiares, económicos, religiosos y de paisanaje que conferían al grupo una gran cohesión interna, típica del marranismo portugués.

El castigo inquisitorial fue terrible. Isabel de Acosta se ahorcó en su celda, temiendo quizás correr la misma suerte que dos de sus amigas, relajadas en persona. Luis López pudo salvar la vida, pero fue condenado a cárcel y hábito perpetuo e irremisible con confiscación de bienes ${ }^{26}$.

Fonseca y dos de sus hermanos, inculpados también por el Santo Oficio, vieron suspendidas sus causas ante lo débil de las acusaciones contra ellos. Uno de ellos, Antonio, estaba instalado como mercader en Valladolid, donde se congregaba una importante representación de negociantes conversos portugueses tras la ubicación de la Corte en esta ciudad. Los otros dos, Andrés y Gaspar de Fonseca, estaban estudiando en Salamanca, de donde prudentemente se habían ausentado con el pretexto de ir a «visitar» a sus familiares en Mirandela, lo cual les permitió escapar de la Inquisición vallisoletana que había votado su prisión en 1604.

Tras pasar la tormenta, ambos volvieron a Castilla y comenzaron a realizar numerosas gestiones en la Corte para obtener la libertad de su padre, al socaire de las negociaciones que allí sostenían los representantes de los judeoconversos portugueses con Felipe III para obtener un perdón general de los delitos de fe. Obtenido este en 1605, Fonseca y su padre lo aprovecharon para

26 AHN, Inq., Leg. 2042 (expts. 29 y 41), con las relaciones de causas referentes a la complicidad de Verín en 1602; véase también Leg. 2884, con cartas sobre el mismo tema. 
ir a Mirandela donde obtuvieron «letras testimoniales» de haber gozado de la gracia del perdón ${ }^{27}$.

Lavadas las culpas de fe, Fonseca regresó a Salamanca donde ese mismo año de 1605 obtuvo el título de doctor en Leyes por el Colegio de Cuenca. Su futuro se presentaba muy prometedor merced a su enlace, concertado unos años antes, con la hija del influyente doctor Enríquez. Este matrimonio le permitiría situarse en una excelente posición dentro de la red clientelar de la poderosa casa de Alba. El casamiento obedecía a una clara estrategia del médico señorial quien trataba de casar a sus hijas con titulados universitarios de origen portugués, judeoconversos y muy probablemente judaizantes. Su hija Leonor casó en primeras nupcias con el licenciado Serrano y, posteriormente, con el licenciado Méndez de León. Otra de sus hijas, Violante, matrimonió con el doctor Diego Gómez de Fonseca, médico de Alba de Tormes y hermano de Andrés, en un enlace doble, característico entre los conversos portugueses, para reforzar la solidaridad interna del grupo ${ }^{28}$.

La boda se celebró en Madrid en 1607. El padrino fue el mismísimo duque de Alba, quien como regalo a los recién casados otorgó a Fonseca el corregimiento de Salvatierra de Tormes. Este primer cargo fue el inicio de su «cursus honorum» al servicio de la casa de Alba. Entre 1609 y 1622 ocupó los puestos de alcalde mayor de Alba de los Caballeros, corregidor de Piedrahita, de San Felices de los Gallegos, de Granadilla y desde 1620 de Alba de Tormes, cargo que ya había desempeñado entre 1615 y 1617.

Similar carrera siguió su cuñado, el licenciado Méndez de León. Este se había casado en 1616 con otra hija del doctor Enríquez, viuda a su vez de otro corregidor de la casa de Alba, y entró a servir en el aparato administrativo ducal como corregidor de Alba (1618-1619) para pasar después a ocupar el mismo puesto en el Barco de Ávila (1620-1622).

El empleo por la nobleza de conversos en sus administraciones fue bastante frecuente en los siglos XV y XVI, práctica que se mantuvo tras la llegada masiva de portugueses a fines del XVI y en el

27 AHN, Inq., Leg. 2042 (expts. 29 y 41).

28 ADC, Inq., Legs. 418 (expt. 5868), 410 (expt. 5766) y 483 (expt. 6513). Vid. LÓPEZ BELINCHÓN Honra. 
XVII. Tal afirmación viene ratificada con ejemplos como los del mayordomo del duque de Velada, el recaudador del duque de Alburquerque, el tesorero del conde de Benavente o los administradores de las haciendas de los duques de Alba y Osuna. Todos esos cargos los conocemos por haber sido ellos, o sus familiares directos, procesados por la Inquisición por judaizantes, lo cual indicaría claramente que la nobleza no tuvo prejuicios para tomar conversos a su servicio ${ }^{29}$.

Dicha relación entre nobleza y conversos era beneficiosa para ambos. Como ya se dijo, los cristianos nuevos lograban a través de ella ocupar un puesto privilegiado en la red clientelar nobiliaria y un ascenso social que les estaba vedado por otros caminos. Por otro lado, la nobleza obtenía hombres de confianza, auténticas criaturas que debían su posición y a veces su fortuna a su protección. Un estudio detallado del personal de los aparatos administrativos señoriales sería muy esclarecedor.

La dedicación de Fonseca a sus tareas de gobierno en los diferentes puestos que ocupó no le impidieron cultivar otras relaciones muy útiles en un futuro. La ciudad de Valladolid y su Chancillería eran un lugar de visita obligada en un sociedad tan pleiteadora. Fonseca acudió a la ciudad castellana en 1616, siendo corregidor de Granadilla. Allí se aposentó en casa de Bartolomé López Téllez, donde conoció y comenzó a tratar a su hermano Fernando Montesinos a quien ayudó en un pleito que tenía por haber metido moneda falsa en Castilla. Montesinos y sus hermanos habían creado una extensa red comercial familiar con ramificaciones en Portugal y Francia, inserta a su vez en otra más amplia de mercaderes portugueses (como Juan Núñez Saravia, Luis Fernández Pato o los hermanos Rodríguez Lamego) dedicada tanto a negocios lícitos como ilícitos. Años después, ya en Madrid, Montesinos le designaría como su abogado ayudándole así a rehacer su vida, honra y hacienda ${ }^{30}$.

Desde que abandonó la casa paterna de Verín y especialmente tras el tropiezo familiar con la Inquisición, Fonseca trató de ocul-

29 LÓPEZ BELINCHÓN Honra.

30 ADC, Inq., Leg. 445 (expt. 6238); vid. LÓPEZ BELINCHÓN Honra. En el proceso que en 1633 se incoó en Cuenca contra Fernando Montesinos, Fonseca apareció como testigo de descargo. 
tar su origen portugués, siempre tan sospechoso, tras una supuesta ascendencia gallega. Debió lograr, sin duda, su objetivo pues casi ninguno de sus acusadores pudo asegurar que fuese portugués, aun cuando todos coincidieron en que pese a ser gallego era cristiano nuevo. Un testigo declaraba que «le tiene en opinión de cristiano nuevo de judío y todos sus hermanos» porque en San Esteban de Valdeorras «le dijeron en el mesón que habían venido a coger la farda, tributo que los judíos pagan a Su Majestad y se la habían pedido a un hermano del doctor Fonseca». Sabemos que estos datos eran rotundamente falsos, pero cuando el fin era el descrédito social la veracidad de los rumores no era lo más importante ${ }^{31}$.

Dos hermanos de Fonseca, Antonio y Diego, decidieron que la mejor manera de huir del pasado era poner un océano por medio. En 1613 obtuvieron sus expedientes de limpieza para pasar a las Indias gracias a las declaraciones falsas de varios testigos portugueses. Ambos se instalaron en Guatemala, donde se les unió una hermana que allí casó con un caballero de Santiago, descendiente de los conquistadores ${ }^{32}$. Verín parecía ya muy lejos ${ }^{33}$.

Estos expedientes de limpieza los utilizó el corregidor Fonseca en un intento de demostrar su limpieza de sangre y se reforzaron con las declaraciones de varios testigos portugueses residentes en Madrid, entre ellos Manuel Núñez Navarro, futuro arrendador de la renta de los naipes de Castilla, involucrado en la red comercial portuguesa de que era partícipe Montesinos, y Juan López Leonel, cliente y amigo del ya citado Fernando Montesinos.

Pero todo fue en vano, su pasado le había alcanzado. Los archivos del Santo Oficio, celosos guardianes de la memoria y arma básica de la lucha contra los conversos, pronto lo sacaron a la luz dando con ello más fuerza a las acusaciones que se le imputaban.

Las denuncias llegadas al tribunal de Valladolid motivaron el envío a Alba de un comisario de Salamanca para tomar las declaraciones pertinentes. El licenciado Martínez Zúñiga se mostró

31 ADC, Inq., Leg. 418 (expt. 5868).

32 ADC, Inq., Legs. 418 (expt. 5868) y 487 (expt. 6536).

33 Años después un hijo de Fonseca hizo lo mismo que sus tíos, pero acabó en la hoguera inquisitorial en El Callao; vid. J. CARO BAROJA, Los judios en la España Moderna y Contemporánea (Madrid 1978, 2ª ed.) pág. 223. 
desde el primer momento sumamente obsequioso con él, proporcionándole testigos contra Fonseca y «estando noche y día en la puerta del mesón del comisario». A finales de febrero de 1622 Valladolid envió estas testificaciones a la Suprema que en 11 de marzo ratificó los votos de prisión de los inquisidores vallisoletanos contra el grupo de Alba.

Mientras esto sucedía, el corregidor Fonseca lanzó su contraataque «para persuadir que aquella vocera era de sus enemigos y no de la verdad». Hizo grandes diligencias en Madrid buscando favores e intercesiones y en Valladolid presentó ante el tribunal del Santo Oficio una querella criminal contra las personas que le pareció podían ser testigos contra él y sus cómplices ${ }^{34}$.

Para realizar estas gestiones recabó el apoyo de su cuñado el licenciado Méndez de León, corregidor del Barco, quien en Madrid contactó con el confesor del duque de Alba para que intercediese ante la Suprema ${ }^{35}$. En la propia villa aprovechó su cargo para presionar a sus enemigos - Antonio Rodríguez denunció ante el comisario del Santo Oficio las molestias de que era objeto por parte del corregidor - a la par que movilizaba a adictos como el licenciado Nogal, comisario del Santo Oficio de Alba, que fue amonestado por los inquisidores por su falta de secreto.

El esfuerzo fue inútil. El 15 de marzo de 1622 se votó su prisión con secuestro de bienes. Junto a él fueron también votados su hermano, el doctor Diego López de Fonseca, futuro médico de D. Juan José de Austria; las esposas de ambos, D. ${ }^{a}$ Isabel y D. ${ }^{a}$ Violante Enríquez, hijas del doctor Enríquez; el hermano de estas, D. Rodrigo Enríquez, alcalde mayor por el Duque de Alba en la villa de Granadilla, y su madrastra, D. ${ }^{a}$ Blanca Enríquez, dama de la duquesa de Huéscar. Al mismo tiempo se apresó a D. ${ }^{a}$ Catalina de Alburquerque, esposa del corregidor señorial de Castro Nuevo; a D. ${ }^{a}$ Ana Rodríguez y a Isabel de Paredes, las tres portuguesas, vecinas de Alba y unidas por una fuerte amistad a la familia del doctor Enríquez. Todos ingresaron en las cárceles secretas del Santo Oficio en Valladolid.

34 AHN, Inq., Legs. 3210 y 3211.

35 ADC, Inq., Leg. 410 (expt. 5766). 
Sólo D. Rodrigo Enríquez escapó a la redada, ocultándose entre el séquito del duque de Alba que marchaba a Nápoles para ocupar el puesto de Virrey. Parece que el propio duque no le permitió que se embarcase con él en Vinaroz hacia Italia, quizás porque era demasiado comprometido ayudar a un fugitivo de la Inquisición. Tras este fracaso intentó esconderse en Madrid donde finalmente fue apresado en la primavera de $1623{ }^{36}$.

Iniciadas las audiencias con los procesados, muy pronto comenzaron las inculpaciones de unos a otros siguiendo una estrategia muy clara. Se aceptaba algún delito menor para evitar ser considerado negativo por los inquisidores, al tiempo que se incriminaba a otros miembros de la familia o a otras personas, a menudo muertos o inexistentes, en faltas poco graves para demostrar arrepentimiento. Del cruce de confesiones se derivó la prisión del licenciado Manuel Méndez de León, corregidor del Barco de Ávila, y de su esposa, Leonor Enríquez, a principios de julio de $1623{ }^{37}$.

En sus declaraciones los reos reconocieron la práctica de algunos ritos y ceremonias judaicas dentro de la familia, especialmente ayunos, y la intención judaizante de los ritos que acompañaron el entierro del doctor Enríquez. La figura del médico se perfilaba a través de las confesiones como la del líder del grupo criptojudío. $\mathrm{Su}$ formación universitaria le permitía acceder a «lugares de las escrituras y del testamento viejo» para explicar a los demás, entre otras cosas, «la misericordia que Dios había hecho a su pueblo de Israel por medio de la reina Esther librándole gloriosamente de la tiranía» y también «sabía muchos preceptos de la ley» ${ }^{38}$.

El acceso a estas fuentes era especialmente importante en un momento en que los grupos criptojudíos se encontraban aislados y sin posibilidad de recibir formación judaica de las comunidades hebreas del exterior. En este contexto cobran pleno sentido las afirmaciones de Caro Baroja sobre el papel religioso básico del médico en la sociedad criptojudía ${ }^{39}$. Otros galenos lusos como

36 AHN, Inq., Leg. 3210; y ADC, Inq., Leg. 410 (expt. 5766).

37 ADC, Inq., Leg. 410 (expt. 5766).

38 ADC, Inq., Leg. 418 (expt. 5868).

39 «En la sociedad criptojudía el médico representa la actividad intelectual por antonomasia, solía ser el hombre más informado en cuestiones religiosas y filosóficas pues para ejercer su profesión podían ejercitarse en la practica del hebreo, griego y latín y leer libros sospechosos en manos de otros» (CARO BAROJA Inquisición págs. 122-123). 
Fernando Cardoso, alias Isaac Cardoso, o el menos conocido doctor Mercado ratifican tal idea con su comportamiento.

Considerando el papel desempeñado por el doctor Enríquez dentro del grupo familiar judaizante, tiene un especial interés uno de los consejos que daba a sus deudos. Para él lo importante era la Ley que se tuviese en el corazón y no los signos exteriores. Se era observante de la Ley de Moisés aunque no se hiciesen sus ceremonias. Esta actitud nicodemista era necesaria para aparentar una integración en la comunidad cristiana, más formal que real.

Era normal que los judaizantes procesados pareciesen excelentes cristianos en sus actos externos e incluso se vanagloriasen de ello. El corregidor Fonseca alardeaba de ser mayordomo de las cofradías del Santísimo Sacramento y de Nuestra Señora del Rosario. Su esposa y sus cuñadas disimulaban un ayuno judaico asistiendo, en lugar preeminente, a las ceremonias con que se celebraba el día de Santa Teresa en el convento que la santa andariega había fundado en Alba ${ }^{40}$.

Mucho mas espectacular era la actitud del licenciado Méndez de León. En los descargos de su proceso aseguraba ser muy devoto de la Inmaculada Concepción «e hizo que en el Barco se votase su fiesta»; también construyó un humilladero al Cristo del Caño, dio grandes limosnas a los franciscanos y condujo ante la Inquisición a un vecino del Barco que había quemado una cruz. Este comportamiento resulta aun más paradójico si pensamos que el propio licenciado fue relajado por judaizante algunos años después, en 1653. El mimetismo social alcanzado por Méndez de León debió ser tan perfecto que al conocerse las prisiones de sus familiares en Alba todos en el Barco le daban el pésame y nadie de la villa lo acusó tras su prisión. La importancia de los signos externos de religiosidad propia del catolicismo barroco tridentino jugaba a favor de estos grupos judaizantes en sus intentos de integración, al menos formal ${ }^{41}$.

Los procesos de Alba, con todas las singularidades ya descritas, deben inscribirse en un contexto represivo más amplio. Las cárceles secretas de la Inquisición vallisoletana registraron en los primeros años de la segunda década del XVII una alta ocupación. En

40 ADC, Inq., Leg. 418 (expt. 5868).

${ }^{41}$ ADC, Legs. 410 (expt. 5766) y 418 (expt. 5868). 
1620 se había producido la prisión de un importante grupo familiar de judaizantes radicado en Medina de Rioseco y con ramificaciones en Valladolid. En 1625 fueron detenidas 52 personas acusadas de judaísmo y al año siguiente otras $23{ }^{42}$. Estas cifras concuerdan con las que Jaime Contreras da para el tribunal de Galicia y J. P. Dedieu para el de Toledo ${ }^{43}$.

Los datos que ofrece el archivo del Santo Oficio conquense se muestran coincidentes. Entre 1620 y 1629 fueron procesadas por judaísmo 70 personas que contrastan con las 40 de la primera década del siglo y las 31 de los años treinta. De los procesados en la década de los veinte todos eran oriundos de Portugal, excepto dos nacidos en Castilla de padres lusos. La mayoría proceden de la Beira y Tras-os-Montes y habían llegado a Castilla a fines del siglo XVI y principios del XVII dedicándose preferentemente a actividades comerciales ${ }^{44}$. Todo esto nos indica cómo hacia los años veinte el problema judaizante cobró para los inquisidores un renovado protagonismo en íntima relación con el crecimiento de la llegada de emigrantes portugueses.

El aumento del interés del Santo Oficio hacia los siempre sospechosos portugueses explicaría cómo las débiles denuncias de algunos vecinos de Alba, movidos más por objetivos políticos que por celo religioso, encontraron rápido eco en un tribunal especialmente sensibilizado ante la «amenaza portuguesa».

De entre todos los procesos coetáneos a los de Alba incoados en Valladolid merecen especial atención los de la familia Sánchez de Guevara, oriunda de Medina de Rioseco, por los lazos que establecieron más tarde con la familia del doctor Enríquez.

En febrero de 1620 los inquisidores de Valladolid recibieron una carta del Inquisidor General interesándose por el breve despacho de la causa del licenciado Tomas Sánchez de Guevara, médico natural de Rioseco y vecino de Valladolid, y de algunos de sus familiares «y que por ser personas principales se les conmute el castigo en penas pecuniarias o que al menos sea secreto». La respuesta de Valladolid fue áspera: «la calidad de sus personas no es lo que le habrán dicho a su Ilustrísima sino muy ordinaria y que

42 BENASSAR Inquisición págs. 138-139.

43 J. Contreras, El santo Oficio de la Inquisición de Galicia: Poder, sociedad y cultura (Madrid 1981) y DEDIEU L'administration de la foi.

${ }^{44}$ LÓPEZ BELINCHÓN Honra. 
solo tienen el ser favorecidos de personas grandes que se sirven de deudos de estos presos que así de esa Corte como de esta ciudad les favorecen con cartas y de palabra» ${ }^{45}$.

Las características de esta familia parecen coincidir con las del grupo del corregidor Fonseca: buena posición social e importantes valedores. Sin embargo, existe una diferencia fundamental en el hecho de que toda la familia Sánchez de Guevara era natural de Castilla. Nos encontramos así ante un resto de las comunidades judaizantes castellanas supuestamente desaparecidas desde mediados del siglo XVI bajo la represión inquisitorial.

Según informes del propio Santo Oficio los abuelos paternos de los procesados eran naturales de Herrera de Pisuerga y los maternos de Cuenca de Campos. La abuela materna, Ana de Valladolid, era hija de Luis de Valladolid «que llaman el judío del guitarrón y que por su pie había ido a bautizar», y el abuelo tenía como padre a Arias Martínez, «de nación portugués y de casta cristiano nuevo» ${ }^{46}$.

La familia se había establecido en Medina de Rioseco. Sus ocupaciones comerciales no fueron óbice para que los estudios universitarios, una vez más de medicina, fueran una fórmula de ascenso social seguida por alguno de sus miembros. La vida religiosa fue otra salida para una de las hijas, profesa en el convento de Santa Clara en Rioseco. Su integración en la vida local parecía completa. No despertaban las sospechas de sus convecinos, más recelosos de la nutrida comunidad portuguesa asentada en la villa, en algunos casos, como el de la familia del doctor Fernando Cardoso, con la protección directa del duque de Rioseco, señor de la villa.

A diferencia del grupo de Alba fueron las querellas en el seno de la propia familia las que provocaron la intervención del Santo Oficio. El peligro en este caso no provenía del exterior sino que nacía de la ruptura de la cohesión interna. El intento de una mujer de anular su matrimonio acusando a su esposo de judaizante fue el origen de todo. Los intentos de evitar los procesos resultaron baldíos. Como mal menor prefirieron autoinculparse y confesar algunas ceremonias judaicas.

Una vez en prisión usaron en su favor los contactos de Francisco Angulo, suegro del licenciado Sánchez de Guevara, «solicitador

45 AHN, Inq., Leg. 3209.

46 ADC, Inq., Leg. 404 (expt. 5713). 
de causas en la Chancillería y como tal sirve en su oficio a muchos grandes y por este medio tienen muchos valedores». Los inquisidores de Valladolid sufrieron el interés por los procesos del conde de Benavente, del marqués de Aguilar, de la duquesa de Nájera y del conde de Luna. En Madrid, el marqués de los Vélez «y otros muchos particulares» hacían sentir su presión sobre la Suprema con los resultados que ya vimos más arriba ${ }^{47}$. De nuevo la nobleza protegía a sus agentes, muchos de ellos conversos. Las sentencias, merced a su postura de colaboración y a la intercesión de sus valedores, fueron leves y se conmutaron a los pocos meses mediante el pago de sumas que oscilaron entre los cuarenta y cien ducados ${ }^{48}$.

Los procesados de Alba fueron reconciliados unos meses después, el 18 de agosto de 1624. Su actitud durante el proceso había facilitado el rápido despacho de las causas, pero las sentencias fueron, en su mayoría, duras. El corregidor Fonseca fue condenado a ser reconciliado en auto público con confiscación de bienes y cárcel y hábito perpetuos. Similar pena recayó sobre su suegra, D. ${ }^{a}$ Blanca Enríquez, segunda esposa del doctor Enríquez, y con varios familiares reconciliados por judaizantes a fines del XVI. La esposa del corregidor, Isabel Enríquez, ante la actitud negativa que adoptó para proteger a su marido fue votada a ser relajada. Una vez en el cadalso donde tenía lugar el auto de fe pidió audiencia y, sabiendo a salvo a su marido, confesó. Fue condenada a ser reconciliada en auto público con hábito y cárcel perpetua e irremisible, confiscación de sus bienes y cien azotes. Más suaves fueron las penas para el licenciado Méndez de León y su esposa, ambos castigados a ser reconciliados en auto público más dos y un año respectivamente de cárcel y hábito y confiscación de sus bienes.

No todos los hijos del doctor Enríquez salieron tan mal parados del tropiezo con la Inquisición. D. Diego Enríquez no fue apresado en la redada y continuó su carrera eclesiástica disfrutando de varios beneficios simples en los estados de Alba.

Ninguna de las sentencias, como era común en la época, se cumplió en su integridad. D. ${ }^{a}$ Blanca Enríquez compró, pocos meses después de ser reconciliada, su habilitación por cuarenta ducados y su hija Leonor, esposa de Méndez de León, la obtuvo

47 AHN, Inq., Leg. 3209.

48 AHN, Inq., Leg. 3210. 
sin pagar nada. Imaginamos que el corregidor Fonseca hizo lo mismo, pues en agosto de 1625, tan solo un año después de haber sido reconciliado, la Suprema conmutó su sentencia y la de su esposa por penas espirituales ${ }^{49}$.

Obtenida la libertad, Fonseca y su mujer se instalaron en Madrid tratando de huir del descrédito y de volver a ocultar su pasado. En la Corte pronto comenzó a ejercer como abogado de varios miembros de la comunidad de «hombres de negocios» portugueses. En especial trabajó para Fernando Montesinos, su antiguo amigo de Valladolid, ahora importante hombre de negocios que actuaba como arcaduz de las redes de contrabando creadas por la comunidad sefardí de Holanda y futuro preso de las cárceles del Santo Oficio conquense ${ }^{50}$.

El licenciado Manuel Méndez de León se avecindó en Toro como abogado desde donde se trasladó a Madrid en 1639. En 1641 casó allí con D. ${ }^{a}$ Ana Sánchez de Guevara, natural de Medina de Rioseco y procesada junto a varios de sus hermanos en Valladolid en 1620. En la capital se ganaba la vida como abogado y testaferro de poderosos hombres de negocios portugueses.

Una hermana de D. ${ }^{a}$ Ana Sánchez de Guevara, D. ${ }^{a}$ Isabel, también procesada en Valladolid, contrajo matrimonio con D. Rodrigo Enríquez, hijo del doctor Enríquez, quien finalmente logró pasar a Nápoles al servicio del duque de Alba ${ }^{51}$.

Enlaces como estos entre familias de judeoconversos originarias de Castilla y las de Portugal fueron frecuentes y contribuyeron a reforzar con lazos de parentesco la cohesión del grupo frente a la mayoritaria sociedad cristiano vieja. Al mismo tiempo el más activo criptojudaísmo de las familias de origen luso sirvió para revitalizar las comunidades judaizantes castellanas, como la de Medina de Rioseco, en pleno proceso de integración.

Con el paso del tiempo nuestros protagonistas parecían haber logrado hacerse olvidar, pero en los años cincuenta una amplia redada inquisitorial que afectó a buena parte de la elite judeoconversa madrileña les llevó a las cárceles del Tribunal conquense del

\footnotetext{
49 Las sentencias se conservan en sus respectivos procesos. Para aquellos cuyos procesos no se conservan, vid. AHN, Inq., Leg. 3210.

50 ADC, Inq., Legs. 483 (expt. 6513) y 487 (expt. 6536).

51 ADC, Inq., Legs. 483 (expt. 6513), 487 (expt. 653), 404 (expt. 5714) y 484 (expt. 6519).
} 
Santo Oficio. En algunos casos la prisión se saldó con la muerte, como en el del licenciado Méndez de León y su esposa $\mathrm{D}^{\mathrm{a}}$ Ana Sánchez de Guevara, relajados ambos, uno en Granada y la otra en Cuenca ${ }^{52}$.

Tras este nuevo proceso Fonseca y su esposa huyeron de España en 1656 para acabar sus vidas como judíos públicos en Liorna ${ }^{53}$. Uno de sus hijos, el licenciado Luis Enríquez de Fonseca, médico como su abuelo materno, volvió a los orígenes familiares. Ocupó una cátedra en la facultad de medicina de la Universidad de Nápoles en 1681 y publicó, al igual que el doctor Enríquez, varios libros médicos y de literatura ${ }^{54}$. Gozó de la protección del marqués de Castelforte, D. Sebastián López de Hierro y Castro, presidente de la Sumaria de Nápoles, y de su primo D. Sebastián Cortizos, embajador en Génova, miembros ambos de una importantísima familia de conversos portugueses algunos de cuyos miembros fueron procesados por judaizantes en Cuenca en los años cincuenta.

Medicina, universidad, publicaciones y la protección de importantes valedores, aunque ahora conversos, se repiten otra vez en esta familia de judeoconversos portugueses.

Esta aventura personal y familiar muestra cómo los judeoconversos, tanto los de origen castellano como los que llegaron procedentes de Portugal, buscaron en las estructuras clientelares de las grandes casas nobiliarias protección social frente a las posibles amenazas inquisitoriales o de la sociedad cristiano vieja. Al mismo tiempo, el servicio a la nobleza podía ofrecer interesantes posibilidades de ascenso social que por otras vías resultaban más difíciles. Como ya señalamos más arriba, los nobles obtenían por su parte un personal preparado y fiel, pues debía su posición a su ayuda y protección.

Este feliz maridaje de intereses no exento de tensiones fue muy importante para los conversos hasta el asentamiento en Castilla de las grandes casas de negocios lusas en una operación estatal que se asemejaba bastante a la relación conversos-nobleza. Olivares

52 ADC, Inq., Legs. 483 (expt. 6513), 487 (expt. 653), 404 (expt. 5714) y 484 (expt. 6519); LÓPEZ BELINCHÓN Honra.

53 AHN, Inq., Leg. 1896 (expt. 2).

54 Tratado y discurso sobre la moneda del Reino de Nápoles (Nápoles 1681), Ocios de los estudios, Versos y discursos filosóficos (Nápoles 1683) y Regnatium optimo exemplari, Novae securae curationis podagrae (Nápoles 1687). 
les ofrecía cierta protección y posibilidades de grandes negocios y los banqueros le ayudaban y financiaban. A partir de ese momento los conversos portugueses más modestos prefirieron insertarse en las redes clientelares de sus poderosos paisanos sin que eso supusiese que muchos olvidasen a sus antiguos valedores ni que estos prescindiesen totalmente de ellos.

\section{RESUMEN}

A partir del procesamiento por el Santo Oficio de Valladolid de un corregidor señorial y de su familia hemos tratado de explicar la relación que se estableció entre los conversos lusos que comenzaron a llegar a Castilla a finales del siglo XVI y la nobleza, en especial aquella con territorios cerca de la frontera lusa. Este caso también sirve para desde una perspectiva microhistórica analizar las tensiones entre las elites locales y la administración señorial y sus agentes. En esa sorda pugna, argumentos como la limpieza de sangre o un supuesto criptojudaísmo eran de gran importancia y podían determinar la intervención de la Inquisición. De este modo, el Santo Oficio se veía implicado más en una lucha entre facciones locales que en la persecución de la herejía.

\section{SUMMARY}

After the indictment by the Holy Office at Valladolid of a seigniorial corregidor and his family, we have tried to explain the relationship established among the converted Portuguese that started to come to Castile at the end of XVI century and the nobility, specially those whose territories were near the Portuguese frontier. From a microhistorical point of view, this case can also be helpful to analyze the tensions among elite classes and the seigniorial administration and its agents. Arguments as the blood cleanness or a supposed criptojudaism had a great importance and could determine the intervention of the Inquisition. Under these circumstances, the Holy Office was more implicated in a fight between local factions than in a heresy persecution. 